\title{
4
}

\section{Effect of Niobium on HAZ Toughness of HSLA Steels}

\author{
E. El-Kashif ${ }^{1}$ and T. Koseki ${ }^{2}$ \\ ${ }^{1}$ Department of Mechanical Design and Production Engineering, Cairo University, Giza, \\ 2Department of Materials Engineering, The University of Tokyo, Hongo-Bunkyo-ku, \\ ${ }^{1}$ Egypt \\ 2Japan
}

\section{Introduction}

The microstructure of HSLA steels depends on the steel composition and thermomechanical processing route. With the recent trend towards lower carbon contents,

niobium's effect on transformation behavior has been noted with the emergence of acicular or bainitic steels. Under certain conditions, such as utilizing low interstitial contents and high austenizing temperatures, small $\mathrm{Nb}$ additions increase hardenability by depressing Ar3 transformation temperature. Many disagreements exist, however, on the effect of $\mathrm{Nb}$ on the HAZ toughness of HSLA steels. These disagreements include the cause of HAZ embrittlement in steels containing $\mathrm{Nb}$. Some controversy exists in the literature concerning the influence of $\mathrm{Nb}$ on $\mathrm{HAZ}$ properties under certain conditions.

Numerous investigations (Bhadeshia et al., 1985; Nakasugi et al.,1981; Ohtani et al., 1983; Sham, 1985; Yang \& Bhadeshia, 1989,1991) have discussed the effect of $\mathrm{Nb}$ addition on the properties and microstructure of HAZ in low Carbon - microalloyed steels. $\mathrm{Nb}$ is reported to be beneficial as it expands the non-recrystallization temperature range which is useful in plate rolling, furthermore, it increases the hardenability which lead to retardation of GB ferrite and enhancement of intragranular ferrite formation in low heat input HAZ (Yang et al., 1999). Other works reported that $\mathrm{Nb}$ is detrimental as it increases the hardenability, enahances widmanstätten ferrite and upper bainite and enhances the MA formation on the interlath and reheated region. Its effect on the hardness increase due to precipitation of fine $\mathrm{Nb}(\mathrm{C}, \mathrm{N})$ was also reported (Hattingh \& Pienaar, 1998).

The effect on HAZ microstructure varies with composition, welding heat input and etc., two researchers (Tanaka \& Kosazu, 1977) reported that HAZ of SAW 0.06 C-1.5 Mn-Cu-Ni steel contains more MA than $0.1 \mathrm{C}-1.5 \mathrm{Mn}-\mathrm{Cu}-\mathrm{Ni}$ steel in the presence of MA. Other researchers (Sakui et al., 1977) found that the increase in Nb linearly increases MA in 0.1 C-1.5 Mn HAZ.

Many researchers have investigated the effect of $\mathrm{Nb}$ on the HAZ toughness. Some researchers (Fujibayashi \& Endo, 2002; Yamamoto et al., 1984) found that small addition of $\mathrm{Nb}$ decreases toughness however other researchers (Yasuhara et al., 1999; Kawano et al., 2004) found that no significant effect of $\mathrm{Nb}$ addition in case of low $\mathrm{C}$ steels. In the first research (Yasuhara et al., 1999) it was reported that small addition of $\mathrm{Nb}(0.02 \% \mathrm{Nb})$ 
increases toughness in Low C steel. In the other research (Kawano et al., 2004) it was observed that $\mathrm{Nb}$ content more than $0.02 \%$ decreases toughness especially for high heat input welds. On 1999, a research (Kusabiraki et al., 1999) confirmed the former results; in low c steels $(0.03 \mathrm{C})$, small addition of $\mathrm{Nb}(0.02 \%)$ improves toughness, while in medium C steels $(0.07 \%)$, addition of $\mathrm{Nb}$ decreases toughness monotonously.

Two researchers (Hattingh \& Pienaar, 1998) studied the weld HAZ embrittlement of $\mathrm{Nb}$ containing C-Mn steels and they found that: (i) the C content determine the toughness properties in general and tends to be particularly detrimental to HAZ toughness at higher $\mathrm{C}$ levels $(0.19 \% \mathrm{C})$ in combination with $\mathrm{Nb}$, (ii) $\mathrm{Nb}$ doesn't have a significant effect on HAZ toughness at low $\mathrm{C}$ levels $(0.06 \% \mathrm{C})$ during high heat input thermal cycling, (iii) good toughness properties can be obtained at intermediate $\mathrm{C}$ levels of $0.12 \%$ with intermediate to high $\mathrm{Nb}$ additions at lower heat input of 1.5 and $3 \mathrm{KJ} / \mathrm{mm}$, (iv) High C levels $(0.19 \% \mathrm{C})$ combined with a low heat input result in the formation of untempered brittle martensite and lower bainite with poor toughness properties. A research (Fujibayashi \& Endo, 2002) reported that small addition of $\mathrm{Nb}(0.01 \%)$ significantly degrades $\mathrm{HAZ}$ toughness due to promoting MA while another research (Sugimoto et al., 2000) reported that toughness is mainly controlled by $\mathrm{C}$ equivalent and $\mathrm{Nb}$ has little effect in CG-HAZ. Other research (Furuya et al., 2000) reported that high $\mathrm{C}-\mathrm{Nb}$ free steels shows better crack tip opening displacement (CTOD) values than low $\mathrm{C}-\mathrm{Nb}$ bearing steels.

There is conflicting interest among researchers about how $\mathrm{Nb}$ affects MA formation in CGHAZ and how MA affects HAZ toughness. (Ohya et al., 1996) investigated the microstructures relevant to brittle fracture initiation at the HAZ of weldment in low C steel. They concluded that the brittle fracture initiation sites are mostly associated with intersections of bainitic ferrite areas with different orientations. They added that MA is not likely to play an essential role in the brittle fracture initiation. However, they didn't investigate the effect of steel composition on MA content as they used only one steel composition. On the contrary, (Li et al., 2001) emphasized that the presence of MA phase is the dominant factor in determining the toughness of intercritically reheated coarse-grained HAZ. In addition, they found correlations between the toughness and area fraction of MA phase. The presence of MA is widely reported as the main factor in determining the HAZ toughness. Due to the conflict mentioned above among researchers, the present study was carried out in order to reveal the effect of MA formation on the HAZ toughness of the low carbon - microalloyed steels.

\section{Experimental work}

The investigation involved eleven different steels. Plain C-Mn steel was chosen as the base metal. To find out the effect of $\mathrm{Nb}$ addition to different $\mathrm{C}$ equivalent, three groups of steels have the same Mn content with three levels of $C(0.05,0.1$ and 0.15 mass\%) were prepared. Each group has three steels, One without $\mathrm{Nb}$ addition and for the other two, $\mathrm{Nb}$ was added by 0.015 and 0.03 mass \% respectively. Each group of the three groups has different $C$ equivalent which is $0.3,0.35$ and 0.4 respectively. The carbon equivalent is expressed as: Ceq. $=\mathrm{C}+\mathrm{Si} / 24+\mathrm{Mn} / 6+\mathrm{Ni} / 40+\mathrm{Cr} / 4+\mathrm{V} / 14(\mathrm{wt} \%)$. For comparison, two more steels with the same $\mathrm{Nb}$ content (0.015) and different $\mathrm{Mn}$ content were prepared. The chemical compositions of the eleven steels used are given in Table 1. The steels were designated as KT1 KT11. 
The simulated HAZ experiments were carried out for all Steels. The simulation route was chosen to obtain the most adverse HAZ properties. This is obtained by a single thermal cycle with a peak temperature of $1400^{\circ} \mathrm{C}$ representing the high heat input coarse-grained HAZ. The thermal cycle is shown in Fig. 1; the cooling rate between $1400^{\circ} \mathrm{C}$ and $800^{\circ} \mathrm{C}$ is 20 $\mathrm{K} / \mathrm{s}$ followed by cooling rate of $2 \mathrm{k} / \mathrm{s}$ below $800^{\circ} \mathrm{C}$. After the thermal cycle, the Charpy specimens were prepared in the standard form of 10X10X55 mm. Notches are located in the uniform microstructure region at the center of the specimens. Charpy test was carried out at $0,-20$ and $-40{ }^{\circ} \mathrm{C}$ and impact transition curves were constructed.

The optical metallography specimens were prepared and then etched with $2 \%$ nital and Le Pera solution (Le Pera, 1980). Quantitative analysis of MA was conducted for all steels. Both macro and micro-hardness were measured on optical specimens using $10 \mathrm{~kg}$ and $10 \mathrm{~g}$ load respectively. The driving force of $\mathrm{NbC}$ precipitation was calculated using Thermo-Calc version $\mathrm{P}$. The fracture surface of the Charpy specimens was observed using SEM.

\begin{tabular}{|c|c|c|c|c|c|c|c|c|c|}
\hline Steels & C & Si & Mn & P & S & Al & Nb & N & Cequ \\
\hline KT1 & 0.05 & 0.2 & 1.5 & 0.01 & 0.005 & 0.03 & 0 & 0.003 & 0.3 \\
\hline KT2 & 0.05 & 0.2 & 1.5 & 0.01 & 0.005 & 0.03 & 0.015 & 0.003 & 0.3 \\
\hline KT3 & 0.05 & 0.2 & 1.5 & 0.01 & 0.005 & 0.02 & 0.03 & 0.003 & 0.3 \\
\hline KT4 & 0.1 & 0.2 & 1.5 & 0.01 & 0.005 & 0.02 & 0 & 0.003 & 0.35 \\
\hline KT5 & 0.1 & 0.2 & 1.5 & 0.01 & 0.005 & 0.02 & 0.015 & 0.003 & 0.35 \\
\hline KT6 & 0.1 & 0.2 & 1.5 & 0.01 & 0.005 & 0.02 & 0.03 & 0.003 & 0.35 \\
\hline KT7 & 0.15 & 0.2 & 1.5 & 0.01 & 0.005 & 0.03 & 0 & 0.003 & 0.4 \\
\hline KT8 & 0.15 & 0.2 & 1.5 & 0.01 & 0.005 & 0.02 & 0.015 & 0.003 & 0.4 \\
\hline KT9 & 0.15 & 0.2 & 1.5 & 0.01 & 0.005 & 0.02 & 0.03 & 0.003 & 0.4 \\
\hline KT10 & 0.05 & 0.2 & 2.1 & 0.01 & 0.005 & 0.02 & 0.015 & 0.003 & 0.4 \\
\hline KT11 & 0.15 & 0.2 & 0.9 & 0.01 & 0.005 & 0.02 & 0.015 & 0.003 & 0.3 \\
\hline
\end{tabular}

Table 1. The chemical compositions (mass \%) of the steels used.

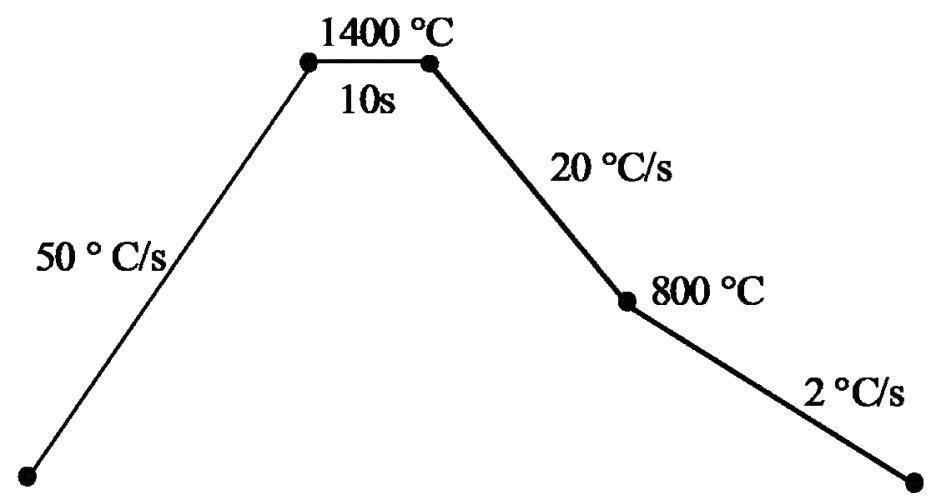

Fig. 1. Thermal cycle of HAZ simulation used. 


\section{Results and discussion}

\subsection{Optical metallography}

Figures 2a $\sim 2 \mathrm{c}$ show the optical microstructure of steels KT4 $\sim$ KT6. All of them have the same carbon content $0.1 \%$ and different $\mathrm{Nb}$ content $0.05,0.1$ and 0.15 respectively. The typical microstructure of the low-alloy steel HAZ is characterized by a very coarse prior austenite grain size with grain boundary ferrite layers and acicular ferrite. The microstructures in Fig. 2 vary according to the chemical composition. Steel KT4 (free $\mathrm{Nb}$ ) consists of large areas of grain boundary ferrite (equiaxed and extended) and widmanstätten ferrite. As the $\mathrm{Nb}$ added, the large areas of allotriomorphic ferrite decreases and the widmanstätten ferrite are replaced by intragranular acicular ferrite as shown for Steel KT5 (medium Nb). Acicular ferrite is recognized in most weld microstructures as intragranulary nucleated bainite. Steel KT6 (high Nb) shows a similar microstructure to KT5 however the increase in $\mathrm{Nb}$ content $(0.03 \%)$ leads to thinner allotriomorphic layers and increases the bainitic products of transformation as well; the intragranular acicular ferrite are replaced by lath structure. The results from optical metallography indicate that the $\mathrm{Nb}$ addition retard $\gamma \rightarrow \alpha$ transformation kinetics and as a result the allotriomorphic layers decrease and the transformation products tend to be bainitic.

Figures $3 \mathrm{a} \sim 3 \mathrm{c}$ show the optical microstructure of steels KT2, KT5 and KT8. All of them have the same $\mathrm{Nb}$ content $(0.015 \%)$ and different carbon content $0.05,0.1,0.15 \%$ respectively. The effect of the increase in Carbon content shows similar effect as the increase in $\mathrm{Nb}$ content for steels KT4 KT6 which have medium carbon content. As the carbon content increases the microstructure varies from widmanstatten ferrite to acicular ferrite and finally bainitic lath structure and the grain boundary ferrite layers decreases. The only difference is that in Steel KT8 (high C - medium Nb), the bainitic structure is more dominant and the grain boundary layer is thinner than Steel KT6 (medium C- high $\mathrm{Nb}$ ).

The dilatometric results, shown in Fig. 4 are in consistent with the microstructure results. Figure 4 shows that the grain boundary ferrite start temperature decreases with $\mathrm{Nb}$ and $\mathrm{C}$ addition, which verify the delaying effect of $\mathrm{Nb}$ on ferrite nucleation. The presence of grain boundary ferrite at the austenite grain boundaries induces the transition from a lath structure, bainite, to acicular ferrite. According to the overall microstructure obtained for the eleven steels, the different steels can be categorized to three categories, namely large grain boundary ferrite with widmnastatten ferrite plus areas of pearlite, which is denoted as category I; thin grain boundary ferrite plus intragranular acicular ferrite which is called category II; and finally the bainitic lath structure which is called category III. It is important to note that the grain boundary ferrite in the last category is very thin and not continuous which means that not all the grains are covered by boundary ferrite. Category I represents the base steel KT1, while category II represents free $\mathrm{Nb}$ - medium and high Carbon steels plus medium $\mathrm{Nb}$ - low Carbon steel. The last category represents $\mathrm{Nb}$ added - medium and high Carbon equivalent steels plus low Carbon - high $\mathrm{Nb}$ steels. A summary of these microstructures is shown in Fig. 5. 


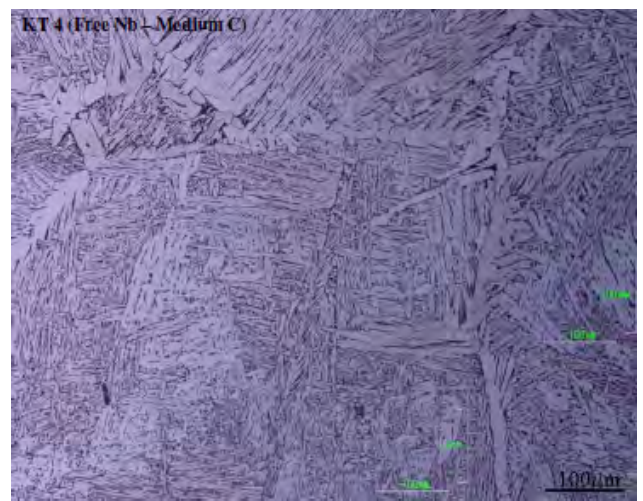

(a)

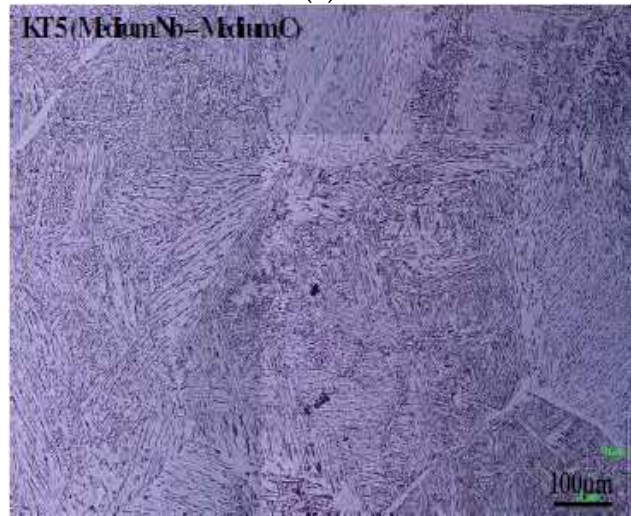

(b)

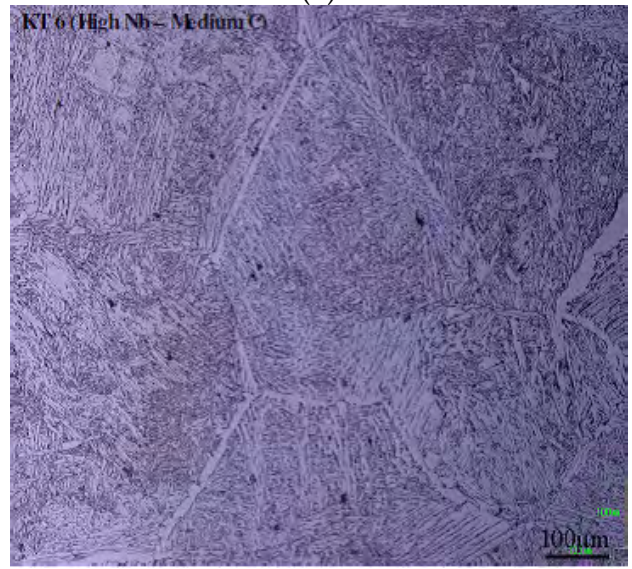

(c)

Fig. 2. (a) Optical photographs of steel KT4 (free Nb- medium C) after simulated cycle (b) Optical photographs of steel KT5 (medium Nb- medium C) after simulated cycle (c) Optical photographs of steel KT6 (high Nb- medium C) after simulated cycle. 


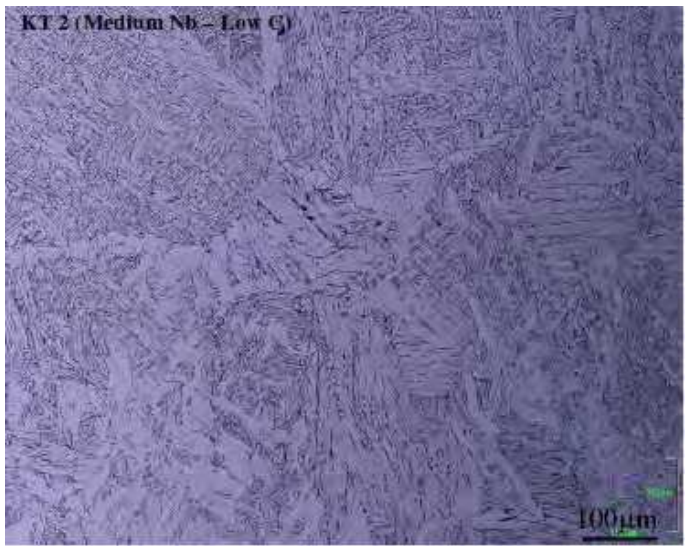

(a)

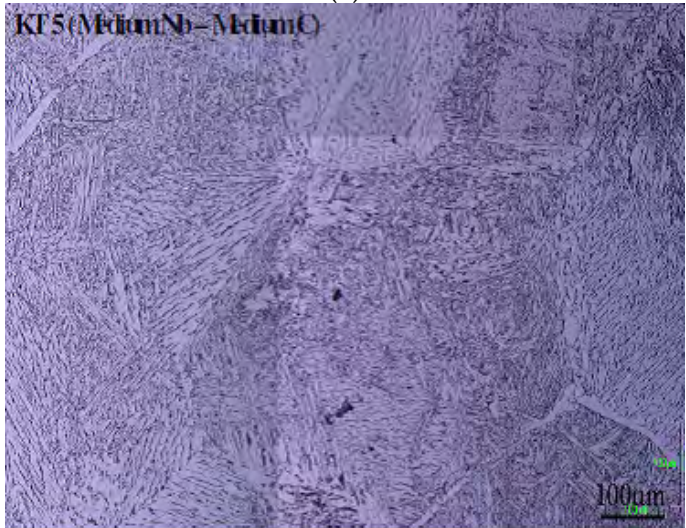

(b)

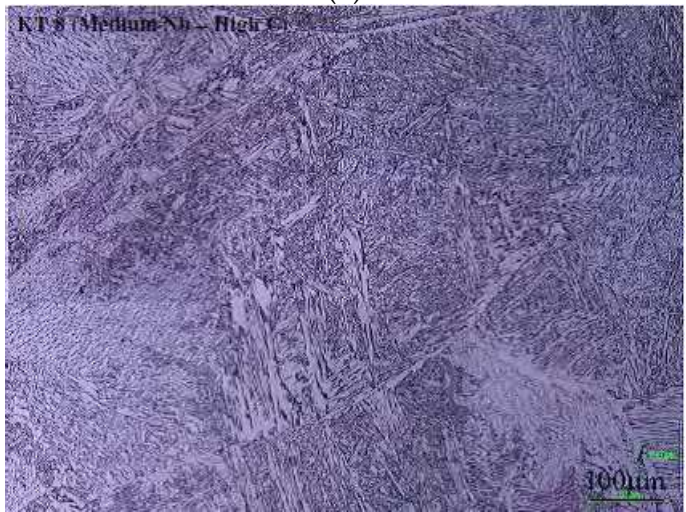

(c)

Fig. 3. (a) Optical photographs of steel KT2 (medium Nb- low C) after simulated cycle.

(b) Optical photographs of steel KT5 (medium Nb- med. C) after simulated cycle.

(c) Optical photographs of steel KT8 (medium Nb- high C) after simulated cycle. 


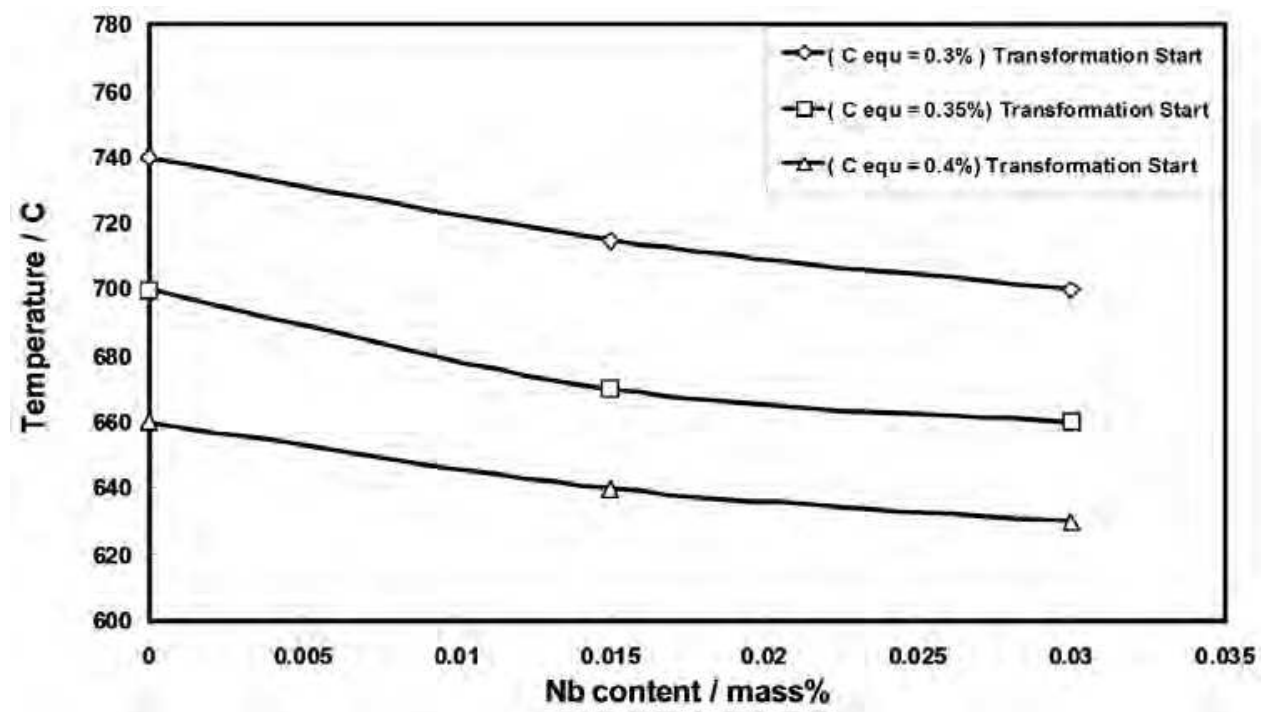

Fig. 4. Effect of $\mathrm{C}$ and $\mathrm{Nb}$ content on the transformation starting temperatures for grain boundary ferrite.

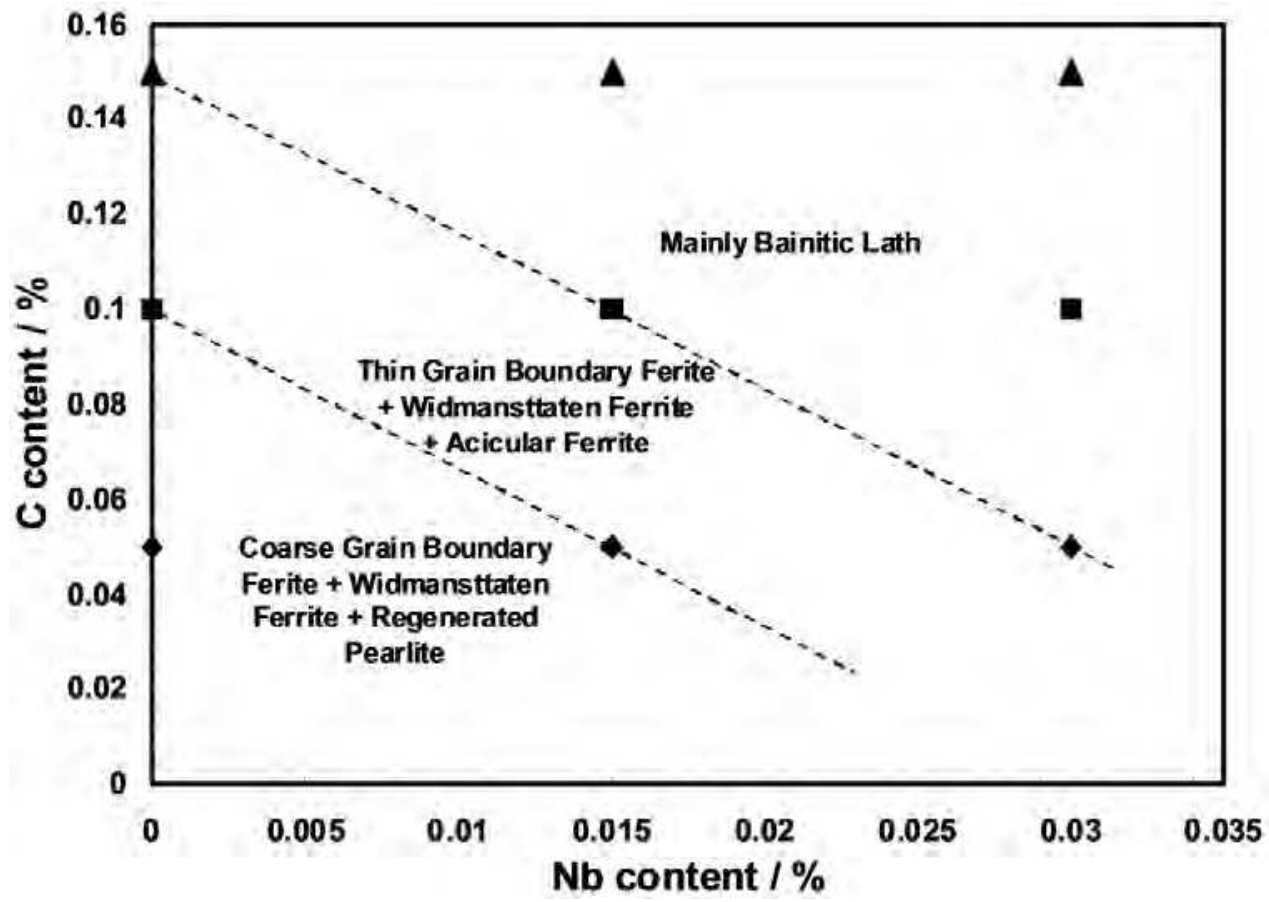

Fig. 5. Summary for the microstructures obtained under different $\mathrm{C}$ and $\mathrm{Nb}$ content for Steels KT1 KT9. 
Figure 6 shows Le Pera etching micrographs for Steels KT1, KT3, KT4, KT6, KT7 and KT9. It appears that the area fraction of MA markedly increases with increasing $\mathrm{Nb}$ content for both low carbon and medium carbon steels, whereas high carbon steels didn't show an increase of MA phase with $\mathrm{Nb}$ content which may be due to the consumption of the $\mathrm{Nb}$ in carbides precipitation.

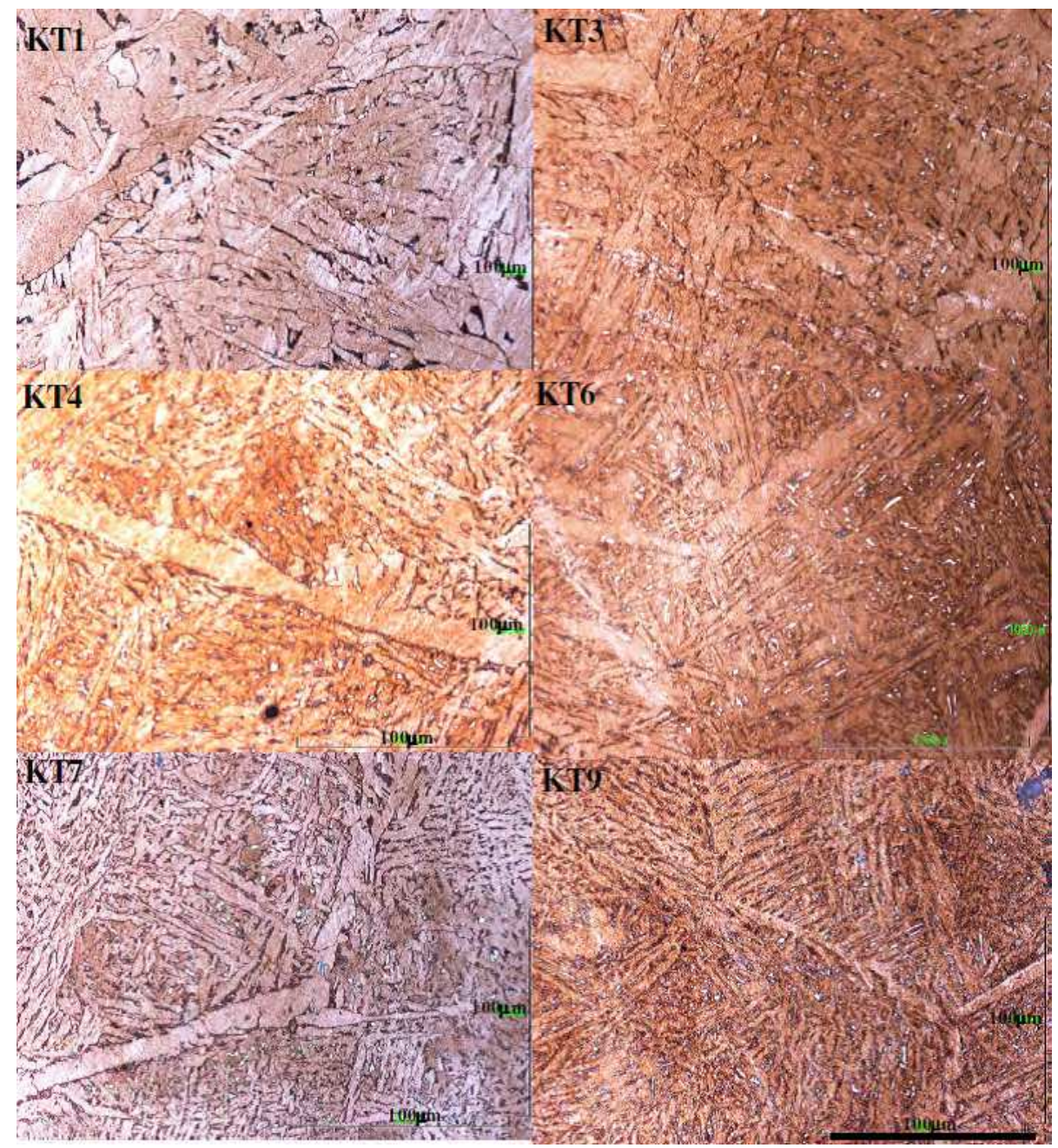

Fig. 6. Optical micrographs of Steels KT1, KT3, KT4, KT6, KT7 and KT9 showing MA after Le Pera etching.

Two researchers (Hattingh \& Pienaar, 1998) observed relatively large undissolved $\mathrm{Nb}$ rich precipitates in $0.12 \% \mathrm{C}-0.06 \% \mathrm{Nb}$ and $0.19 \% \mathrm{C}-0.03 \mathrm{Nb}$ steels, which could have an effect for reducing the MA area fraction for high Carbon steels in the following study. Calculation of the driving force of $\mathrm{NbC}$ precipitation For Fe-C- $1.5 \% \mathrm{Mn}-0.03 \% \mathrm{Nb}$ system using Thermo- 
Calc. showed that the driving force increases with the increase in $\mathrm{C}$ content and shows maximum value at $0.015 \mathrm{C}$ content which is in good agreement with (Hattingh \& Pienaar, 1998) work and can explain the reducing effect of MA area fraction for high carbon Steels.

Figure 7 shows La Pera etching micrographs for Steels KT2, KT11, KT8 and KT10. Steels KT2 and KT11 have the same carbon equivalent $0.3 \%$ but the Mn content is $1.5 \%$ for the former and $0.9 \%$ for the latter. While, Steels KT8 and KT10 have the same carbon equivalent $0.4 \%$ but the Mn content is $1.5 \%$ for the former and $2.1 \%$ for the latter. High Mn content Steel (KT10) shows the highest fraction of MA, however the low Mn content Steel (KT11) doesn't show MA at all.

This implies that Mn content has more detrimental effect on the formation of MA than $\mathrm{Nb}$. It was observed that the distribution of MA for all steels is random and MA concentrates at the interface between grain boundary ferrite and the interior of the grain which consist with the microsegregation mechanism for MA formation proposed by (Furuya et al., 2000). The only steel shows homogeneous distribution of MA is KT10, which has the maximum area fraction as well.

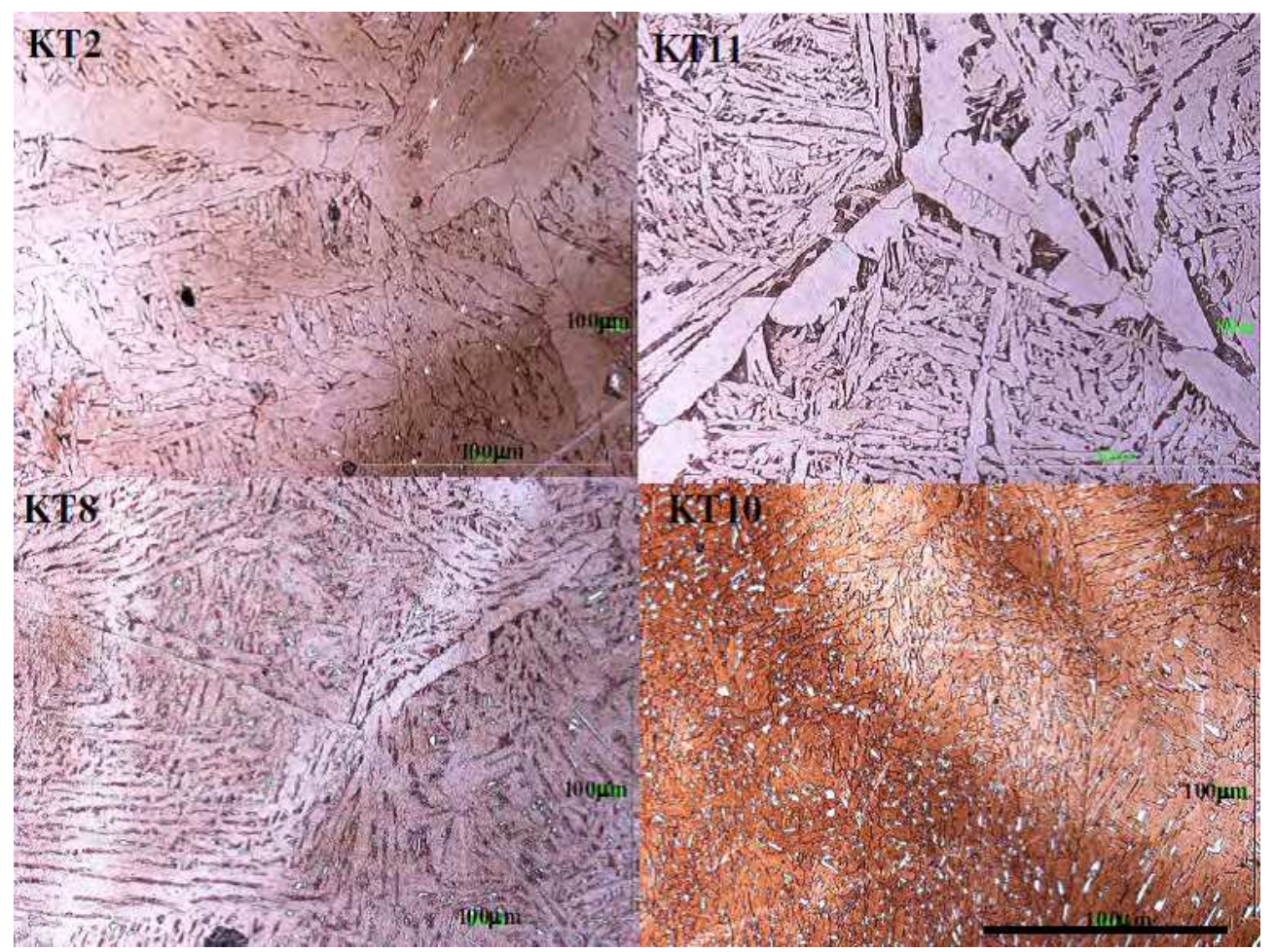

Fig. 7. Optical micrographs of Steels KT2, KT11, KT8 and KT10 showing MA after Le Pera etching.

Figure 8 shows the variation of grain boundary ferrite area fraction with $\mathrm{Nb}$ content for Steels KT1 KT9. It can be shown that the increase in $\mathrm{Nb}$ content for low $\mathrm{C}$ steels shows a 
large decrease in grain boundary ferrite, whereas a slight decrease is resulted for medium and high carbon steels, which may be attributed to the segregation of $\mathrm{Nb}$ to the grain boundaries. (Yasuhara et al., 1999) suggest that because the $\mathrm{Nb}$ atoms have a large misfit within the iron lattice, austenite grain boundaries are favorable sites for the location of niobium atoms and as a result the nucleation and growth of polygonal ferrite will be retarded. The slight decrease in polygonal ferrite for medium and high carbon steels may be attributed to the precipitation of niobium carbides, which consume most of the $\mathrm{Nb}$. The change of Mn and C content within the same carbon equivalent doesn't show a great effect on the allotriomorphic ferrite area fraction.

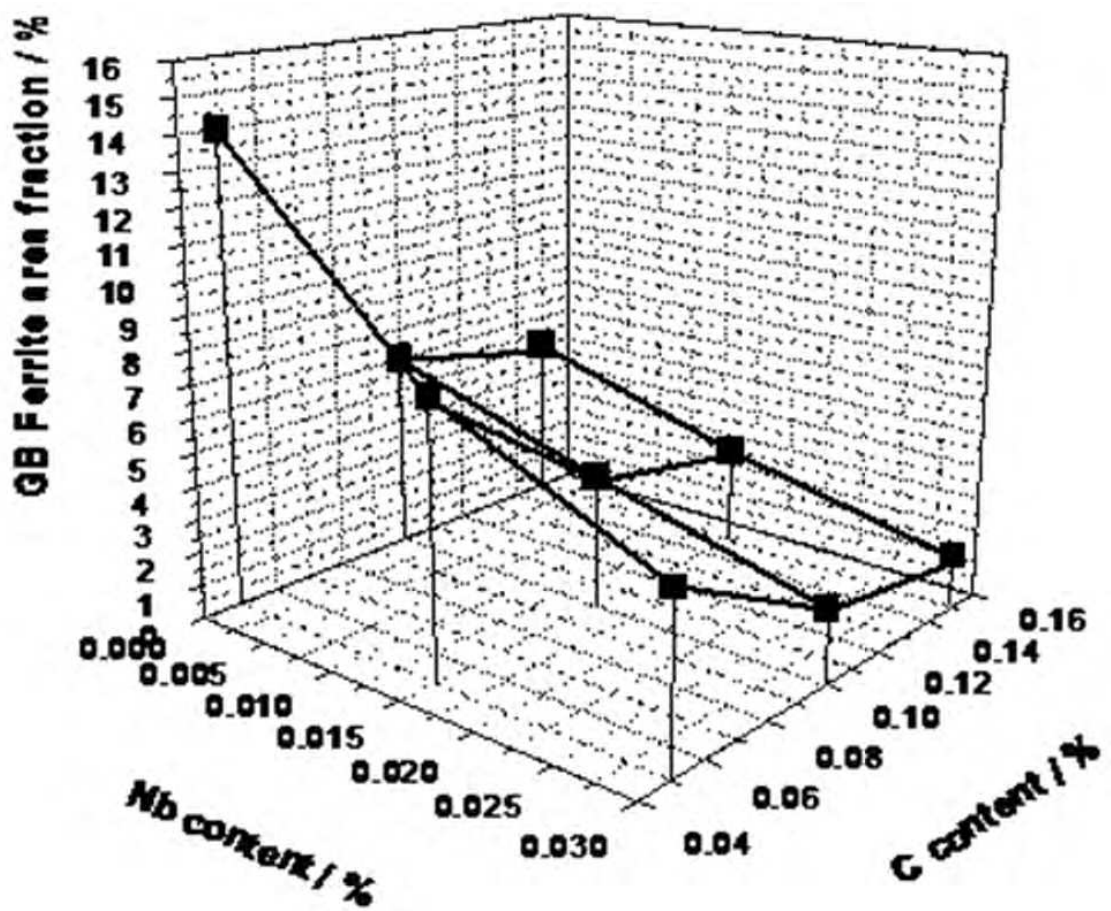

Fig. 8. Variation of grain boundary ferrite area fraction with $\mathrm{Nb}$ content for Steels KT1 KT9.

Figure 9 shows the variation of MA area fraction with $\mathrm{Nb}$ content for steels KT1 $\sim \mathrm{KT} 9$, the increase in $\mathrm{Nb}$ content shows an increase in MA area fraction for low and medium carbon steels but in case of high carbon steels the increase in $\mathrm{Nb}$ content doesn't show an increase in MA area fraction due to the precipitation of niobium carbides as mentioned before.

Figure 10 shows the variation of MA area fraction with the change of $\mathrm{C}$ and $\mathrm{Mn}$ content within the same carbon equivalent. Steels KT2, KT11, KT8 and KT10 have the same Nb content $(0.015 \%)$. The increase in Mn content shows sharp increase in MA area fraction at the same carbon equivalent. Lowering the Mn content to $0.9 \%$, the MA was not observed at all and this was confirmed by more than 15 micrographs. 


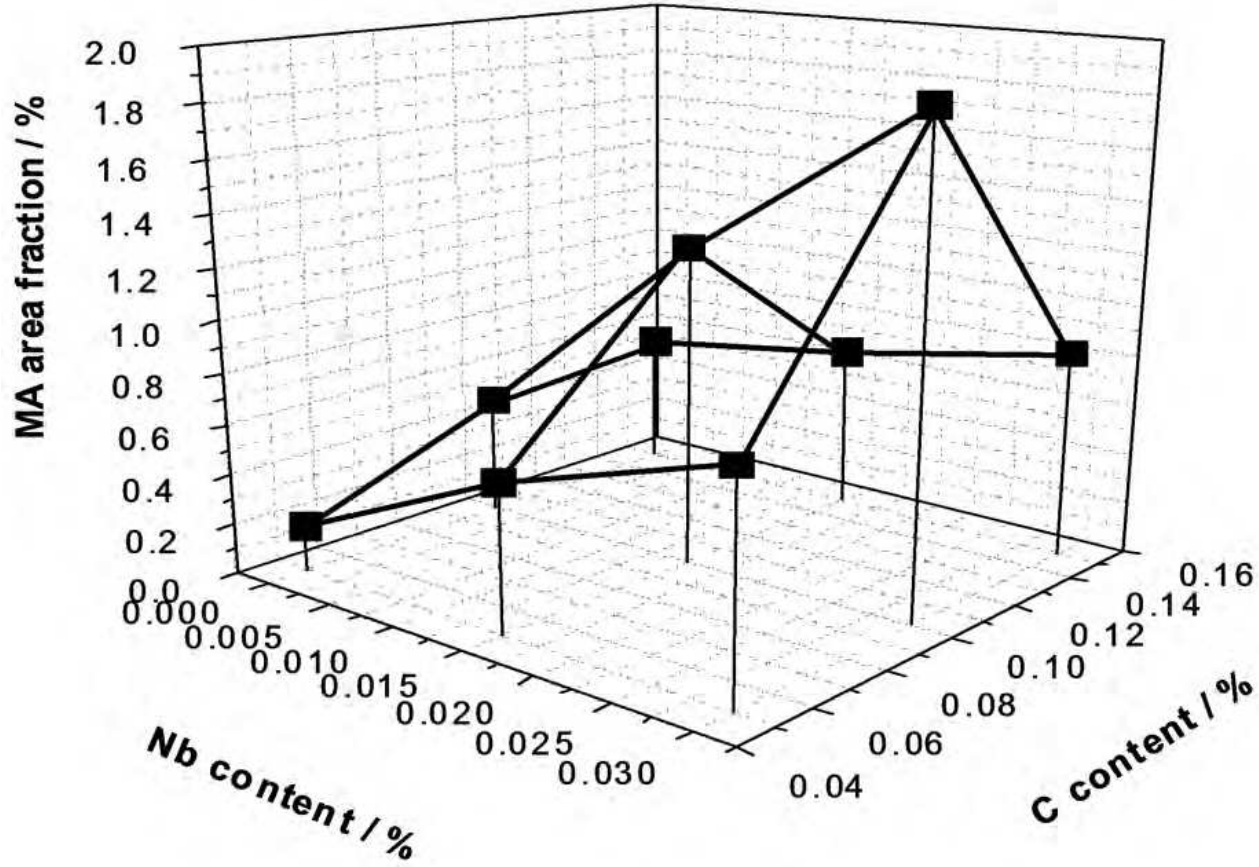

Fig. 9. Variation of MA area fraction with $\mathrm{Nb}$ content for steels $\mathrm{KT} 1 \sim \mathrm{Kt}$.

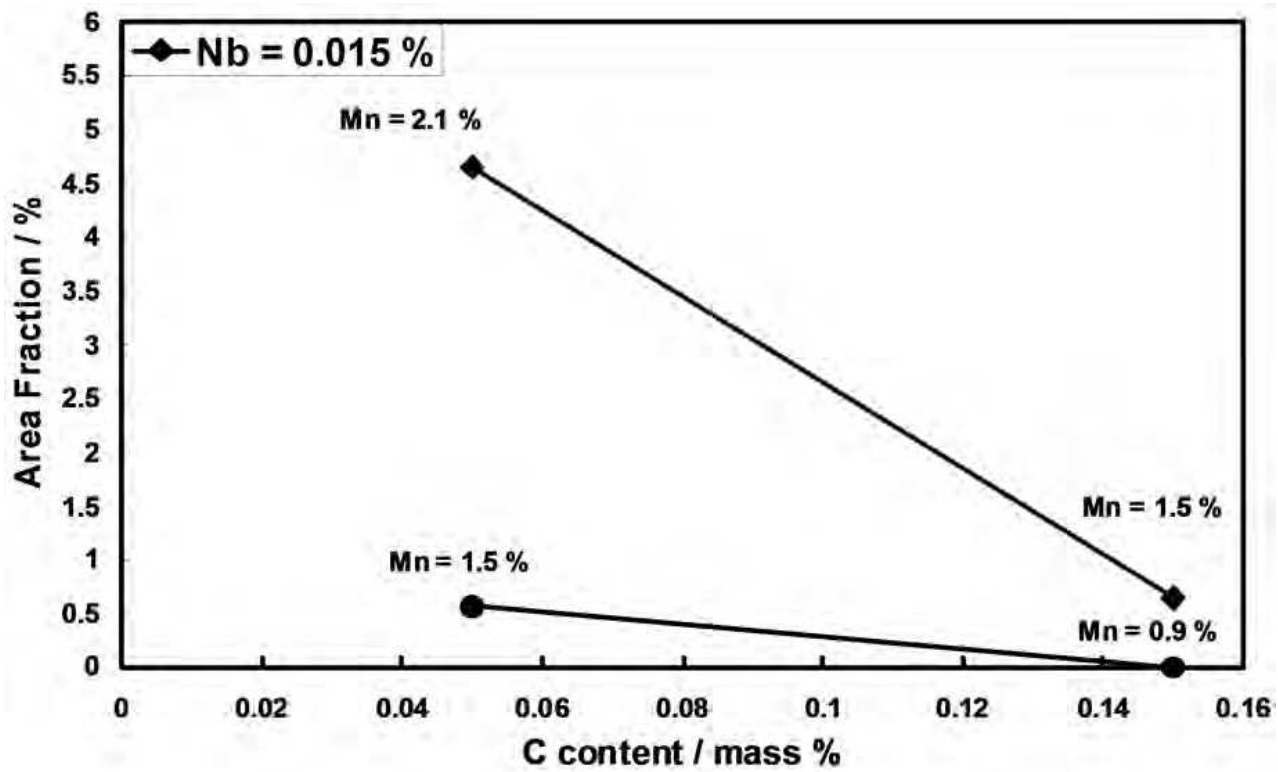

Fig. 10. Variation of MA area fraction with the change of $C$ and Mn content. 


\subsection{Hardness and charpy impact testing}

The variation of hardness with $\mathrm{Nb}$ content for Steels KT1 KT9 is shown in Fig. 11. Hardness of the simulated HAZ increases with increasing $\mathrm{C}$ and $\mathrm{Nb}$ content. The change of hardness is corresponding to the change of microstructure, which was observed before. Figure 12 shows the fracture appearance as a function of test temperature. Steel KT4 (medium $\mathrm{C}$-free $\mathrm{Nb}$ ) shows the lowest transition temperature followed by KT2 (low Cmedium $\mathrm{Nb}$ ) then KT11 (high $\mathrm{C}$ - medium $\mathrm{Nb}$ ). All the three steels have almost the same microstructure, which is grain boundary ferrite and acicular ferrite. Acicular ferrite has been known to provide an optimal combination of high strength and good toughness due to its refined and interwoven structure. They have a similar hardness with similar grain size as well. Steels KT5 and KT6 shows almost the same transition temperature as they have a bainitic microstructure with similar hardness and grain size. Steels KT8 and KT10 show the worst transition temperatures as they have the highest $\mathrm{C}$ equivalent $(0.4 \%)$ but different $\mathrm{Mn}$ and C content. Steel KT10 has the highest MA area fraction but shows a similar transition temperature to KT8, which has low MA fraction, which imply that the microstructure features control the transition temperature and not MA fraction.

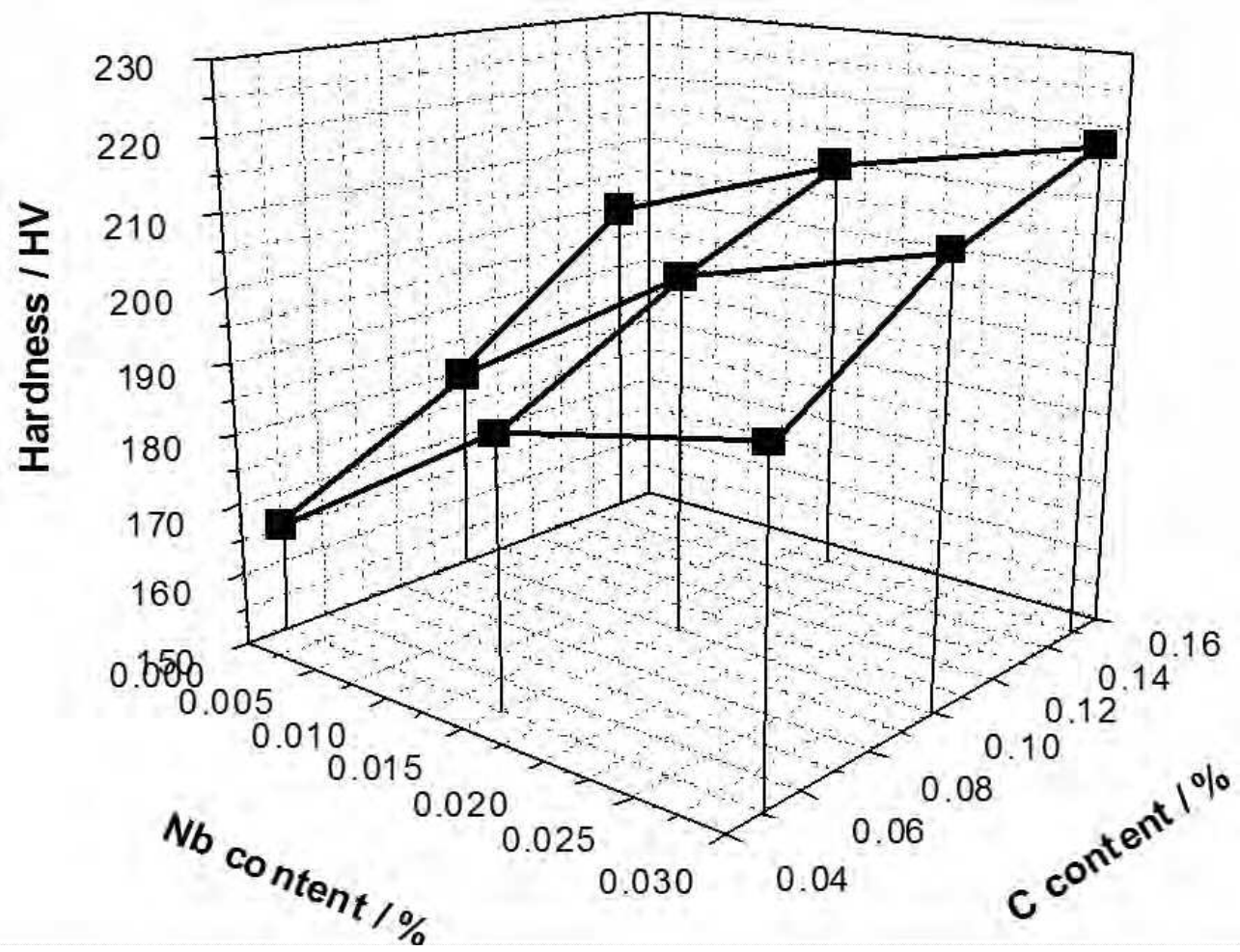

Fig. 11. Variation of hardness with Nb content for Steels KT1 KT9. 


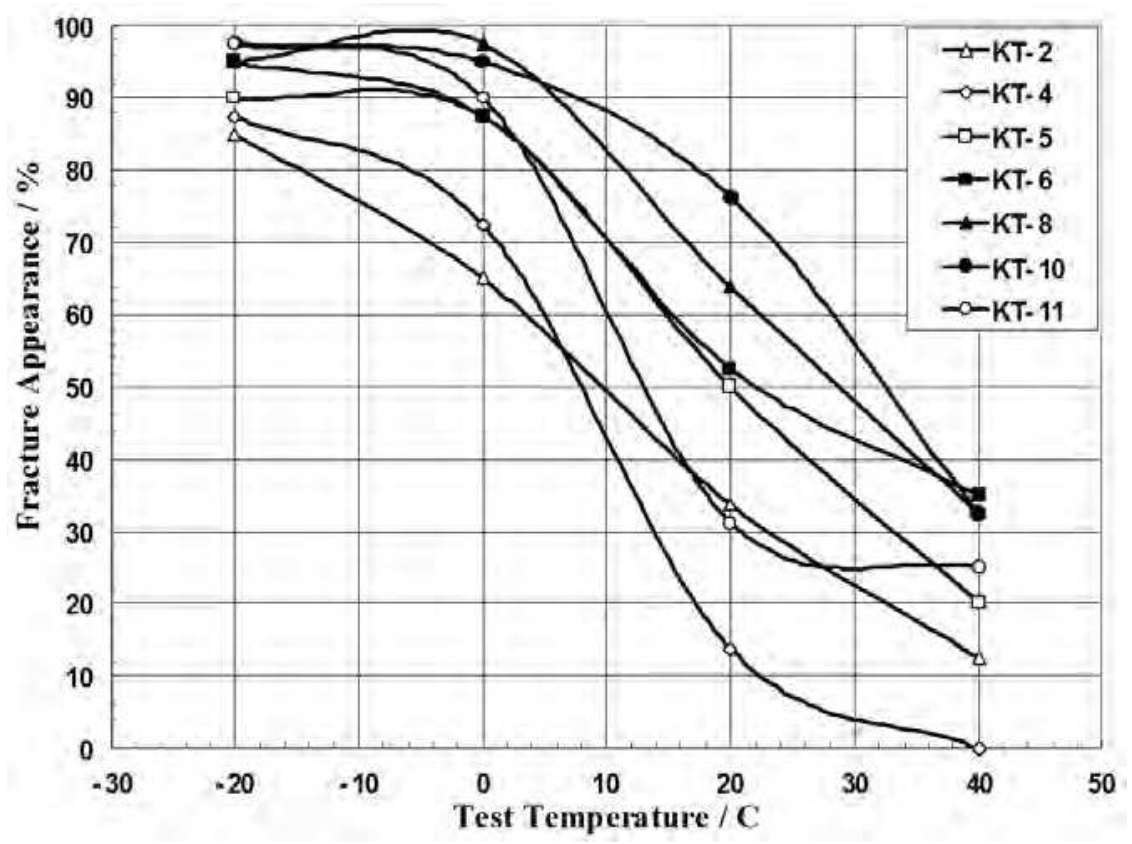

Fig. 12. Fracture appearance as a function of test temperature for some steels.

\subsection{Fracture characteristics}

Fracture characteristics were observed for all steels based on the initiation site of fracture. Three categories of initiation sites were observed based on the microstructure.

Category I, which is the base metal (KT1), the fracture initiates at the regenerated pearlite near grain boundary as shown in Fig. 13. The circle indicates the brittle fracture initiation site.

Category II, was obtained for welds whose microstructure contains relatively large areas of grain boundary ferrite and interior acicular ferrite. To this category belong steels KT2, KT4, KT7 and KT11. In these steels fracture initiates at the grain boundary ferrite. The fracture surface of Steel KT4 is shown in Fig. 14 as an example for this category.

Category III, was obtained at $\mathrm{Nb}$ level of 0.015 and 0.03 with $1.5 \% \mathrm{Mn}$ content, to this category belong Steels KT3, KT5, KT6, KT8, KT9 and KT10. The fracture initiates at the intersection of bainitic packets with different orientation and propagate through the bainitic packets. An example of the fracture surface of this category is shown in Fig. 15.

The transition from one category to another was affected by the $\mathrm{C}$ equivalent and $\mathrm{Nb}$ weld metal levels which affects the microstructure products. Measurements of the fracture unit for samples impact fractured at $-40^{\circ} \mathrm{C}$ shows that all steels have the same fracture unit (around $90 \mu \mathrm{m}$ ) and there is no effect of $\mathrm{Nb}$ on the fracture unit. The existence of pearlite colonies, which is well known with its bad effect on toughness acts as initiation site for the brittle fracture for base steel as pearlite colonies don't exist in $\mathrm{Nb}$ containing steels. 


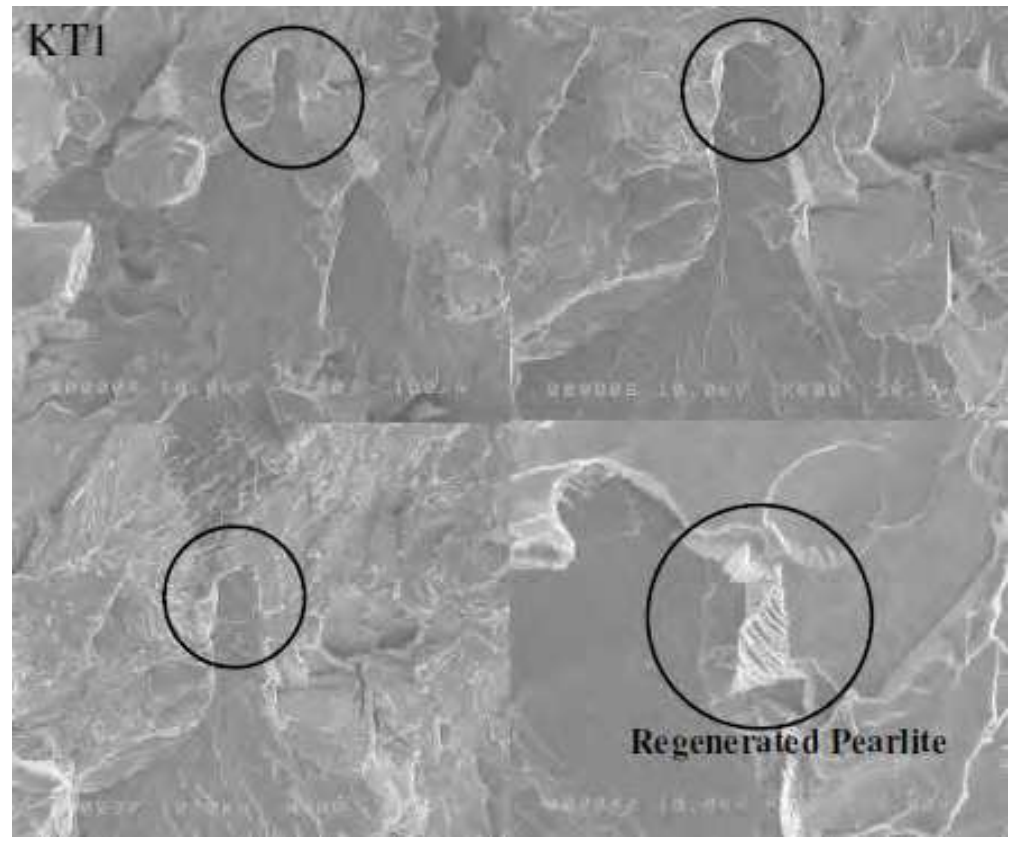

Fig. 13. Fractograph for steel KT1 (base steel).

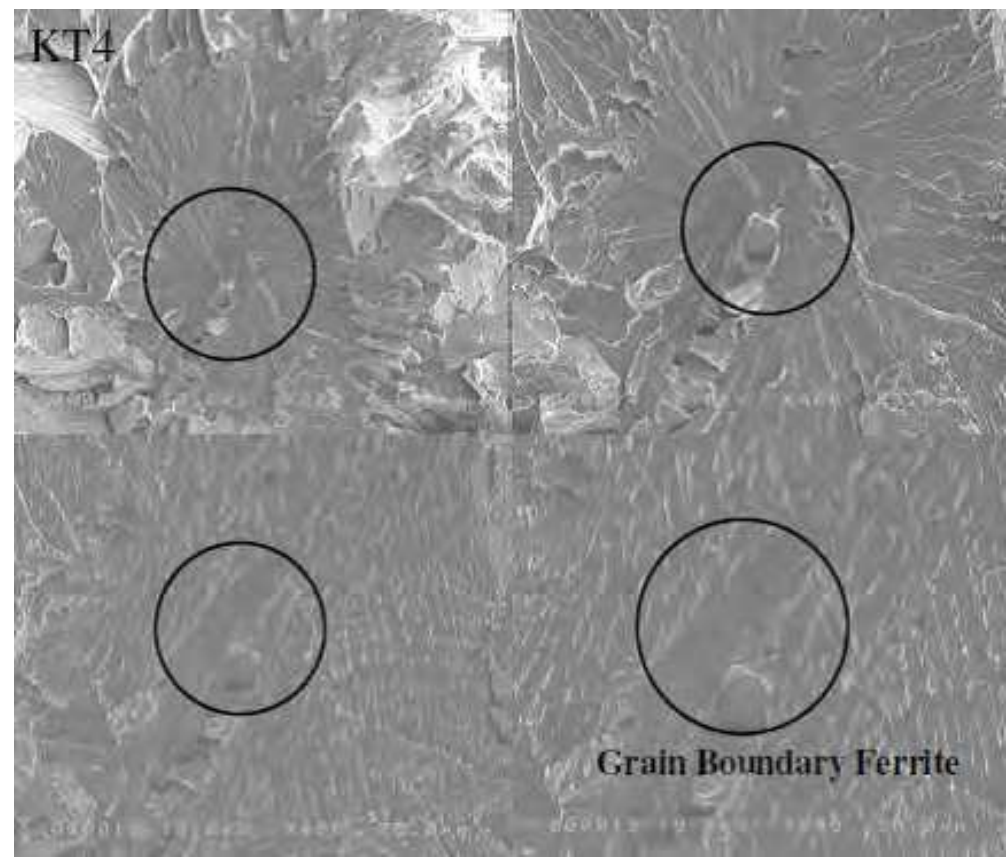

Fig. 14. Fractograph for steel KT4 (medium C-free Nb). 


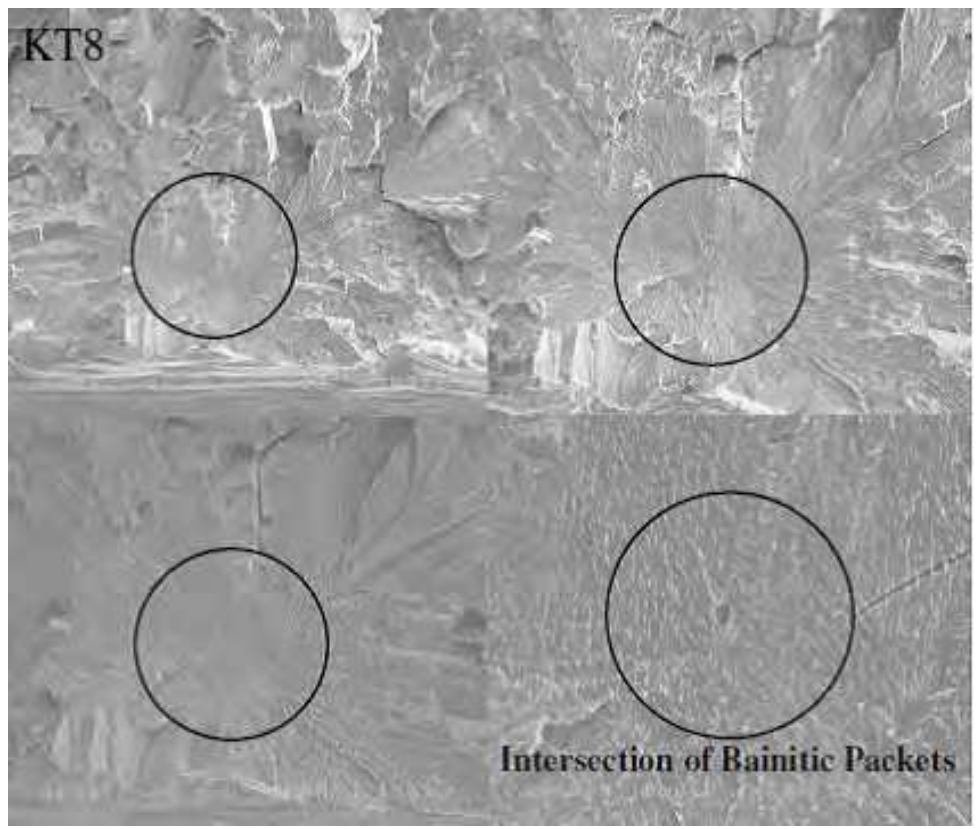

Fig. 15. Fractograph for steel KT8 (high C - Medium Nb).

To correlate between the fracture characteristics and the microstructure obtained for all steels. All the metallurgical aspects have been studied, MA area fraction, grain boundary ferrite area fraction and micro-hardness differences among different phases. It was found that the initiation point of fracture depends on the grain boundary area fraction as shown in Fig. 16.

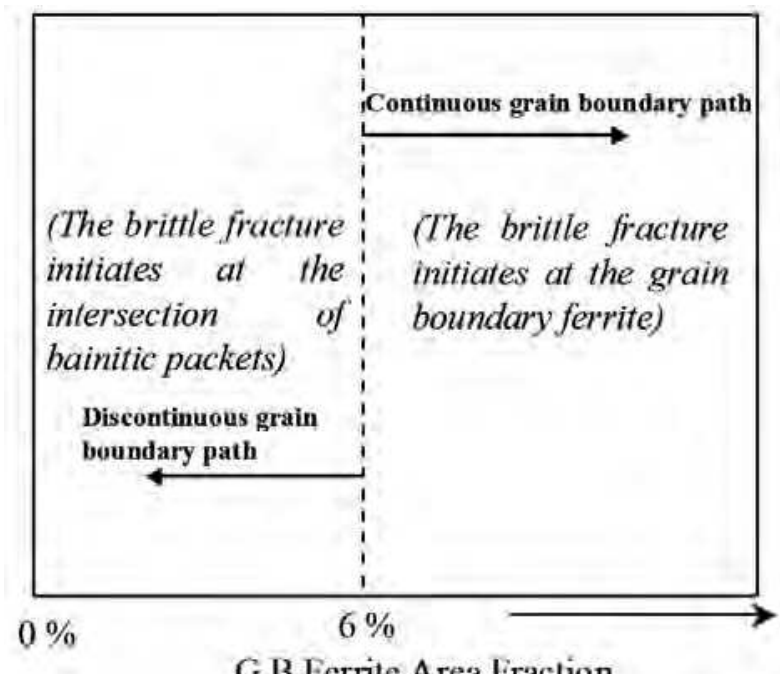

Fig. 16. Relationship between initiation sites and G.B ferrite area fraction. 
There are two fracture characteristics, which is determined according to the grain boundary ferrite area fraction. The first one in which the fracture initiates at the grain boundary ferrite and this happened for steels with grain boundary ferrite fraction than $6 \%$ and the grain boundary ferrite path is continuous. However if the grain boundary ferrite is less than $6 \%$ and discontionus, the fracture initiates at the intersection of bainitic packets. To make sure with this experimental observation, the thickness of grain boundary ferrite layer is calculated for $6 \%$ area fraction for $300 \mu \mathrm{m}$ grain size, it was found that the layer is about 0.03 $\mu \mathrm{m}$. This thickness is with good agreement with the experimental observation and imply that if the area fraction is less than $6 \%$, it will be difficult to cover all the grains which will result in discontinous grain boundary ferrite path and the initiation point will be changed. Steels free $\mathrm{Nb}$ - medium carbon, free $\mathrm{Nb}$ - high carbon and low carbon - medium $\mathrm{Nb}$ steels (KT4, KT7 and KT2 respectively) shows grain boundary area larger than $6 \%$ and this is because the relatively high transformation temperature. The large thickness of grain boundary ferrite with about $100 \mathrm{HV}$ lower microhardness value than the interior of the grain create a stress concentration at the grain boundary ferrite which leads to the brittle fracture initiation at such sites. Although MA was not observed at the initiation sites under SEM, which may be due to debonding during fracture, the concentration of MA observed after Le Pera etching around the grain boundary ferrite for these steels was confirmed by observation of more than 15 positions.

For steels with grain boundary ferrite area fraction less than $6 \%$, the grain boundary path is not continous and the matrix is mainly bainite, the MA has the same alignment as the bainitic laths and the stress is concentrated at the intersection of bainitic packets, which leads to fracture initiation at these intersections. A summary of the microstructure features and corresponding initiation sites are shown in Table 2.

(Hill \& Levine, 1977) emphasized that the relative amount of boundary ferrite and the availability of continuous boundary path determine the initiation of the cracking in their study made on the effects of $\mathrm{Nb}$ and $\mathrm{V}$ on weld metal structure and impact properties.

(Ohya et al., 1996) have studied the microstructures relevant to brittle fracture initiation at the HAZ of low alloy steel $(0.1 \% \mathrm{C}, 1.5 \% \mathrm{Mn}, 0.5 \% \mathrm{Cu}, 0.55 \% \mathrm{Ni}, 0.012 \% \mathrm{Nb})$; they found that the brittle fracture initiation sites are mostly associated with intersections of bainitic ferrite with different orientations. They added that MA constituent is not likely to play an essential role in the brittle fracture initiation.

Some researchers (Ji-ming et al., 2010) have studied the microstructure and mechanical properties of new ultrahigh strength pipeline steel (X120) with high yield strength and high impact toughness. In their work, mechanical properties and microstructure of the steel were investigated. The steel exhibited outstanding mechanical properties with yield strength levels of up to $951 \mathrm{MPa}$ and tensile strength levels up to $1023 \mathrm{MPa}$. The sharp notch toughness with absorbed energy values of $227 \mathrm{~J} / \mathrm{cm} 2$ at $-30{ }^{\circ} \mathrm{C}$ and shear area of up to $95 \%$ in drop weight tear test (DWTT) at temperature of $-20^{\circ} \mathrm{C}$ were achieved. It was found that microstructure of the steel comprises a majority of low-carbon lath bainite with different sublaths and subsublaths, meanwhile there is a high density of dislocation between laths and the dispersed film-like martensite austenite (M-A) constituents. They didn't investigate the phenomenon of M-A formation as they used only one chemical composition which is as following: C 0.05, Mn 1.9, Nb 0.048, Ti 0.015, Mo 0.03, Cr 0.22, B 0.0013, Fe balance. They also didn't investigate the effect of welding on the mechanical properties and microstructure which was investigated in the present work. 
Other researchers (Liang-yun et al., 2011) have studied the correlation between microstructures and mechanical properties of a $\mathrm{Nb}$-Ti micro-alloyed pipeline steel. The results revealed that with decreasing the finish rolling temperature and the cooling stop temperature, the matrix microstructure was changed from quasi-polygonal ferrite to acicular ferrite, as a result of improvement of both strength and low temperature toughness. Their steel was only $1.1 \% \mathrm{Mn}$ and as a result no M-A was observed in it which agrees with the present work.

Darcis et al., 2008 have investigated the crack tip opening angle (CTOA) in five pipeline steels and they concluded that the low carbon $(0.05 \%)$, fine grained ferrite-pearlite pipeline steel has the highest resistance to crack growth. For steels with the same carbon content, the lower Mn contents steels show higher resistance to crack growth which agrees with the present work that the high Mn content has a great effect on MA formation and leads to poor toughness. In weld simulated HAZ, it is difficult to obtain ferrite-pearlite microstructure but Widmnasttaten structure or bainitic structure is usually obtained and it is well known that both Widmnsttaten and bainitic structure have low resistance to crack growth.

As mentioned before, the relative amount of grain boundary ferrite, which is $6 \%$ for these steels determine the fracture behavior, and as a result the toughness. It is important to stress that this relative amount varies according to the chemical composition, thermal cycle and grain size. Therefore this relative amount can't be used for other series of steels with different chemical composition, thermal cycle and grain size.

In the present study, a good correlation between fracture properties and microstructure was established and the confliction among researchers about the brittle fracture initiation sites and its relation to microstructure in $\mathrm{Nb}$ added HSLA could be clarified.

\begin{tabular}{|l|l|l|l|l|l|l|l|l|}
\hline Steel & $\mathbf{C} \%$ & Cequ & $\mathbf{N b} \%$ & $\begin{array}{l}\text { Grain } \\
\mathbf{s i z e} \\
\boldsymbol{\mu m}\end{array}$ & Microstructure & $\begin{array}{l}\text { G.B.F } \\
\%\end{array}$ & MA \% & Initiation Point \\
\hline $\begin{array}{l}\text { Low C- } \\
\text { Free Nb }\end{array}$ & 0.05 & 0.3 & 0 & 348 & $\begin{array}{l}\text { W.F + G.B.F+ } \\
\text { small areas of } \\
\text { Pealite }\end{array}$ & 14 & 0.2 & $\begin{array}{l}\text { Regenerated } \\
\text { pearlite near G.B }\end{array}$ \\
\hline $\begin{array}{l}\text { Low C+ } \\
\text { Nb }\end{array}$ & 0.05 & 0.3 & 0.03 & 207 & Lath Structure & 5 & 1 & $\begin{array}{l}\text { Intersection of } \\
\text { bainitic packets }\end{array}$ \\
\hline $\begin{array}{l}\text { Med. C - } \\
\text { Free Nb }\end{array}$ & 0.1 & 0.35 & 0 & 336 & $\begin{array}{l}\text { G.B.F + W.F + } \\
\text { acicular Ferrite }\end{array}$ & 6 & 0.5 & $\begin{array}{l}\text { At Grain } \\
\text { boundary }\end{array}$ \\
\hline $\begin{array}{l}\text { Med. C + } \\
\text { Nb }\end{array}$ & 0.1 & 0.35 & 0.03 & 248 & Lath Structure & 2 & 2 & $\begin{array}{l}\text { Intersection of } \\
\text { bainitic packets }\end{array}$ \\
\hline $\begin{array}{l}\text { High C - } \\
\text { Free Nb }\end{array}$ & 0.15 & 0.4 & 0 & 342 & $\begin{array}{l}\text { G.B.F + W.F + } \\
\text { acicular Ferrite }\end{array}$ & 6 & 0.5 & $\begin{array}{l}\text { At Grain } \\
\text { boundary }\end{array}$ \\
\hline $\begin{array}{l}\text { High C + } \\
\text { Nb }\end{array}$ & 0.15 & 0.4 & 0.03 & 230 & Lath Structure & 1.8 & 1 & $\begin{array}{l}\text { Intersection of } \\
\text { bainitic packets }\end{array}$ \\
\hline $\begin{array}{l}\text { Low C- } \\
\text { High Mn }\end{array}$ & 0.05 & 0.4 & 0.015 & 236 & Lath Structure & 2.5 & 5 & $\begin{array}{l}\text { Intersection of } \\
\text { bainitic packets }\end{array}$ \\
\hline $\begin{array}{l}\text { High C- } \\
\text { LowMn }\end{array}$ & 0.15 & 0.3 & 0.015 & 330 & $\begin{array}{l}\text { G.B.F + W.F + } \\
\text { acicular Ferrite }\end{array}$ & 6 & 0 & $\begin{array}{l}\text { At Grain } \\
\text { boundary }\end{array}$ \\
\hline
\end{tabular}

Table 2. The initiation sites observed for different steels after impact fractured at $-40^{\circ} \mathrm{C}$. 


\subsection{The formation mechanism of MA}

The grain size for all steels was measured and found to be mainly dependent on the $\mathrm{C}$ equivalent and there is no major change on the grain size for the $0.4 \%$ carbon equivalent steels. For the low carbon equivalent steels (0.3\%), the decrease of Mn content from 1.5 to 0.9 $\%$ results in an increase of grain size by about $20 \%$. Many researchers reported a refining effect for the $\mathrm{Nb}$ on the grain size but for this series of steels, the $\mathrm{Nb}$ content is the same and as a result no effect of the $\mathrm{Nb}$ on the grain size was observed. The change of grain size with $\mathrm{C}$ and Mn content at the same carbon equivalent is shown in Fig.17.

Some researchers (Furuya et al., 2000) proposed a mechanism for the formation of MA, this mechanism is illustrated schematically in Fig.18. It can be summarized in that the grain boundary ferrite causes an enrichment of alloying elements and $C$ at the interface between the grain boundary ferrite and the bainite and also near the interface region. This enrichment is mainly due to the low solubility of alloying elements in ferrite compared to that in austenite. This micro-segregation enhances the formation of $\mathrm{MA}$ or $\mathrm{M}^{*}$ as they named it. To confirm this mechanism, EPMA technique has been carried out for all steels to explain the formation mechanism of MA. The difference in chemical composition of these steels was selected to investigate the effect of change in $\mathrm{Mn}$ and $\mathrm{C}$ content at the same carbon equivalent on MA formation mechanism. A line analysis method with $10 \mu \mathrm{m}$ step was used; the starting point was the center of 10X10X1 mm samples which were subjected to the simulated thermal cycle mentioned before.

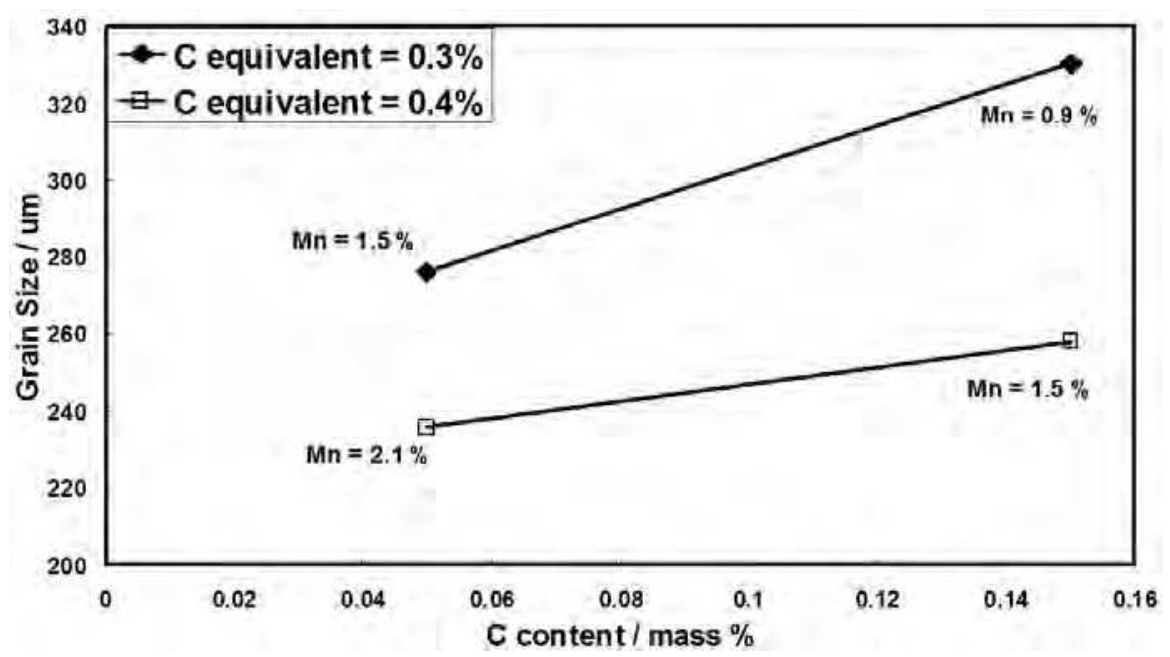

Fig. 17. Effect of $C$ content on the grain size.

The EPMA results for Steel KT4 $(2.1 \% \mathrm{Mn}-0.05 \%$ C) are shown in Figs. 19 and 20. A considerable degree of segregation was obtained for $\mathrm{C}$ and $\mathrm{Mn}$. The degree of $\mathrm{Mn}$ segregation is much higher than that of $C$ which may be attributed to the larger content of $\mathrm{Mn}$. To confirm the furuya's mechanism, steel KT11 $(0.9 \% \mathrm{Mn}-0.15 \% \mathrm{C})$ ) was also examined using EPMA, the degree of Mn segregation was much lower than that of steel KT10 (2.1\% Mn $-0.05 \%$ C) however, the degree of C segregation is higher than that of Steel KT10 (2.1\% Mn $-0.05 \%$ C). This behavior is mainly due to the higher C content of Steel 
KT11 and lower Mn content. From microstructure observation, Steel KT11 shows no MA at all and at the same time, it has a considerable degree of microsegregation for $C$ but low degree for micro segregation for $\mathrm{Mn}$ and this is in good agreement of furuya's mechanism which requires both enrichement of $\mathrm{C}$ and microsegregation of alloying elements as conditions for MA formation. In steel KT11, only the enrichement of C was confirmed by EPMA but the segregation of alloying elements was not obtained in a considerable degree which results in no MA formation. As for $\mathrm{Nb}$, no microsegregation was observed for both steels KT11 and KT10, which may be due to the low content of $\mathrm{Nb}(0.015 \%)$.

Finally, the mechanism proposed by furuya and coworkers was confirmed by good experimental evidence which is the EPMA results of this series of steels.

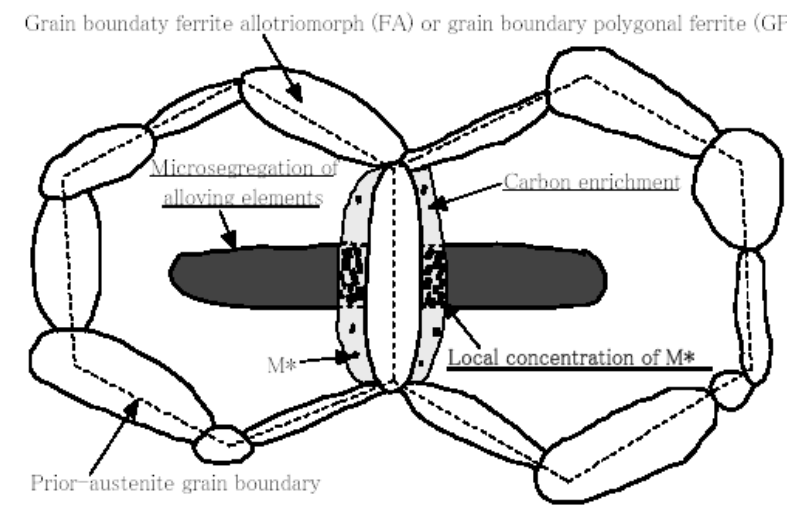

Fig. 18. MA formation mechanism proposed by furuya et al.

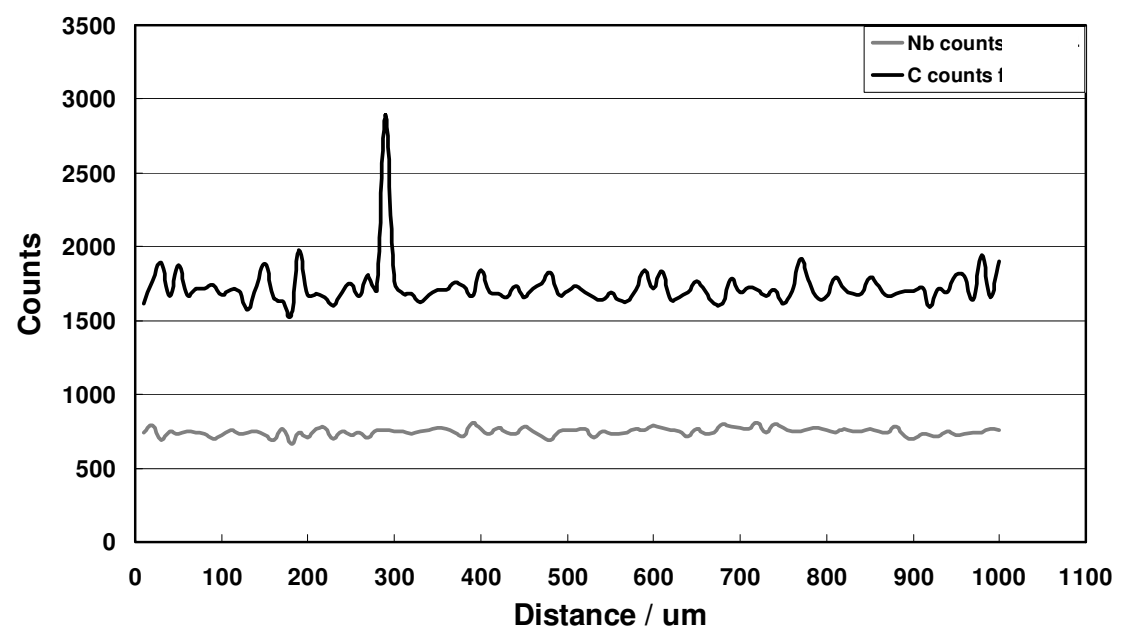

Fig. 19. The EPMA results for $\mathrm{Nb}$ and C for Steel KT10. 


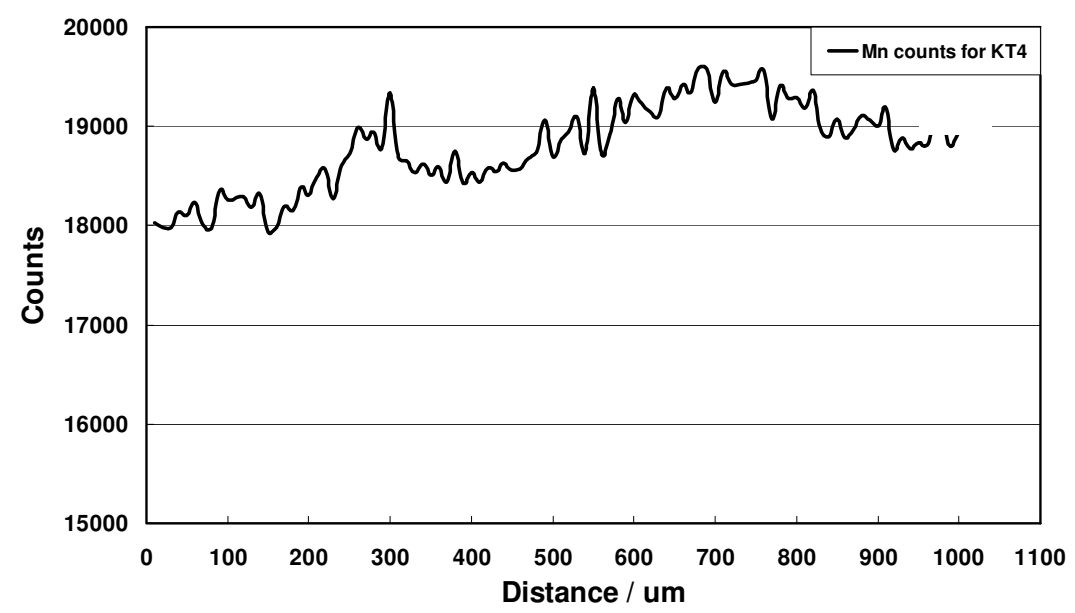

Fig. 20. The EPMA results for Mn for Steel KT10.

\section{Summary}

The effect of $\mathrm{Nb}, \mathrm{C}$ and $\mathrm{Mn}$ on HAZ Toughness of HSLA Steels was investigated, and the following conclusions can be derived:

1. The microstructures of HAZ varies according to the Carbon equivalent and $\mathrm{Nb}$ content and it was found to be consisted of three categories; Category I (base steel), consists of grain boundary ferrite, Widmanstatten ferrite, MA constituents and small areas of pearlite; Category II, consists of grain boundary ferrite, Acicular ferrite, Widmanstatten ferrite and MA constituents; Category III, consists of very thin grain boundary ferrite, lath structure and MA constituents.

2. The CVN transition temperatures reflect the microstructure dependence; category II shows relatively good toughness compared with category III microstructure. The brittle fracture was observed to be initiated at the pearlite colonies, at the grain boundary ferrite and at the intersection of the bainitic packets for the three categories respectively.

3. $\mathrm{Mn}$ is the most dominant element affects the formation of MA at the same Carbon equivalent; lowering the $\mathrm{Mn}$ content to $0.9 \%$ at the same carbon equivalent results in nul MA while increasing it to $2.1 \%$ at the same Carbon equivalent results in large increase in MA area fraction. The area fraction of MA increases by $\mathrm{Nb}$ addition for low and medium Carbon steels but for high Carbon steels, MA area fraction shows a slight increase due to carbides precipitation.

4. A relative amount of grain boundary ferrite, which is $6 \%$ for these steels determine the initiation site, and as a result the fracture behavior and toughness. A good correlation between fracture properties and microstructure was established based on this criterion.

5. The micro-segregation of $\mathrm{C}$ and $\mathrm{Mn}$ at the interface between the grain boundary ferrite and the bainitic matrix could explain the formation mechanism of (MA). Enrichment of C alone near the grain boundary didn't result in MA formations, which imply that both $\mathrm{C}$ enrichment and alloying elements micro-segregation should be achieved simultaneously to form MA. 


\section{References}

Bhadeshia, H. , Sevensson, L. \& Gretoft, B. (1985). A model for the development of microstructure in low-alloy steel (Fe-Mn-Si-C) weld deposits. Acta Metall., Vol. 33, pp. 1271-1283, ISSN 0001-6160

Darcis, Ph. P. ,McCowan, C.N., Windhoff, H. ,McColskey, J.D. \& Siewert, T. A. (2008). Crack tip opening angle optical measurement methods in five pipeline steels. Engineering Fracture Mechanics, Vol. 75, pp. 2453 - 2468, ISSN 0013-7944

Fujibayashi, S. \& Endo, T. (2002). Creep Behavior at the Inter-critical HAZ of a $1.25 \mathrm{Cr}-0.5 \mathrm{Mo}$ Steel. ISIJ Int. ,Vol. 42, No. 11, pp. 1309-1317, ISSN 0915-1559

Furuya, H., Uemori, R., Tomita, Y., Aihara, S. \& Hagiwara, Y. (2000). Ductile crack propagation characteristics and mechanism of structural steel under high strain rate. Technical report by Steel Research Laboratories, Tetsu-to-hagané, Nippon Steel Corporation, Vol. 86, No.6, pp. 409-416, ISSN 0021-1575

Hattingh, R. \& Pienaar, G. (1998). Weld HAZ embrittlement of Nb containing C-Mn steels. International Journal of Pressure Vessels and Piping, Vol. 75, pp. 661-677, ISSN 03080161

Ji-ming, Z., Wei-hua, S. \& Sun Hao, S. (2010). Mechanical Properties and Microstructure of X120 Grade High Strength Pipeline Steel. Journal of Iron and Steel Research International, Vol. 17. No. 10, pp. 63-67, ISSN 1006-706X

Kawano, H., Shibata, M., Okano, S., Kobayashi, Y. \& Okazaki, Y. (2004). TMCP Steel Plate with Excellent HAZ Toughness for High-rise Buildings. RED Kobe Steel Engineering Reports, Tokyo, Vol. 54,pp. 110-113, ISSN 0373-8868

Kusabiraki, K. , Saji, S. \& Tsutsumi, T. (1999). Effects of cold rolling and annealing on the structure of $\gamma^{\prime \prime}$ precipitates in a Ni-18Cr-16Fe-5Nb-3Mo alloy. Metallurgical and Materials Transactions A, Vol. 30 , 1923-1931, ISSN 1073-5623

Le Pera, F. (1980). Metallographic methods for revealing the multiphase microstructure of steels. Journal of Metals, Vol. 32, pp. 38-39, ISSN 1047-4838

Levine, E. \& Hill, D. (1977). Structure- Property relationships in low c weld metal. Metallurgical Transactions A, Vol. 8A, pp.1453-1463, ISSN 1073-5623

Li, Y., Crowther, D., Green, M., Mitchell, P. \& Baker, T. (2001). The Effect of Vanadium and Niobium on the Properties and Microstructure of the Inter-critically Reheated Coarse Grained Heat Affected Zone in Low Carbon Micro-alloyed Steels. ISIJ Int., Vo. 41, No. 46, ISSN 0915-1559

Liang-yun, L., Chun-lin, Q., De-wen, Z. \& Xiu-hua,G. (2011). Microstructural Evolution and Mechanical Properties of Nb-Ti Microalloyed Pipeline Steel. Journal of Iron and Steel Research International, Vol. 18, No. 2, pp. 57-63, ISSN 1006-706X

Nakasugi, H., Matsuda, H. \& Tamehiro, H. (1981). Steels for Line Pipe and Pipeline Fittings. Proceedings of an international conference and held at Grosvenor House, The Metals Society, ISBN 9780904357455, London, October, 1981

Ohtani, H. , Hashimoto, T. \& Kyogoku, T. (1983). HSLA. Steel Technology and Applications. ASM, Philadelphia, PA, p. 843, ISSN 0097-3912

Ohya, K., Kim, J. , Yokohama, K. \& Nagumo, M. (1996). Microstructures relevant to brittle fracture initiation at the heat-affected zone of weldment of a low carbon steel. Metallurgical and Materials Transactions A, 27A , pp. 2574-2582, ISSN 1073-5623

Sakui, S., Sakai, T. and Takeishi, K. (1977). Hot deformation of austenite in a plain carbon steel. Trans. Of Iron Steel Institute Japan, Vol. 17, pp. 718-725, ISSN 0021-1583 
Sham, N. (1985). A comparative study of the HAZ properties of B-containing low alloy steels. Journal of Metals, Vol. 12, No. 21, ISSN 1047-4838

Sugimoto, K., Iida, T., Sakaguchi, J. \& Kashima, T. (2000). Retained Austenite Characteristics and Tensile Properties in a TRIP Type Bainitic Sheet Steel. ISIJ Int., Vol. 40, No. 9, pp. 902-908, ISSN 0915-1559

Tanaka, J. \& Kosazu, I. (1977). Acicular ferrite HSLA for line pipe. Journal of Metal Science and Heat Treatment, Vol. 19, No.7, pp. 559-572, ISSN 0026-0673

Yamamoto, S., Ouchi, C. \& Osuka, T. (1982). The effect of microalloying elements on the recovery and recrystallization in deformed austenite, Proc. Thermo-mechanical Processing of Micro-alloyed Austenite. Ed. by A. J. DeArdo et al., AIME, Warredale, PA, pp.613-619, ISBN 9780895203984

Yang, J. \& Bhadeshia, H. (1989). Orientation relationships between adjacent plates of acicular ferrite in steel weld deposits. Material Science and Technology, Vol. 5, pp.9397, ISSN 0267-0836

Yang, J. \& Bhadeshia, H. (1991). Acicular ferrite transformation in alloy-steel weld metals. J. Mater. Sci., Vol. 26, pp. 839-845, ISSN 0022-2461

Yang, J., Hyang, C. \& Chou, C. (1999). Microstructures of Heat-Affected Zone in Niobium Containing Steels. Materials Transactions, JIM, Vol. 40, No.3, ISSN 0916-1821

Yasuhara, H., Okuda, K., Tosaka, A. \& Furukimi, O. (1999). Carbon-manganese wrought steel with inoculated acicular ferrite microstructure. CAMP-ISIJ, Vol.12, ISSN 09151559 


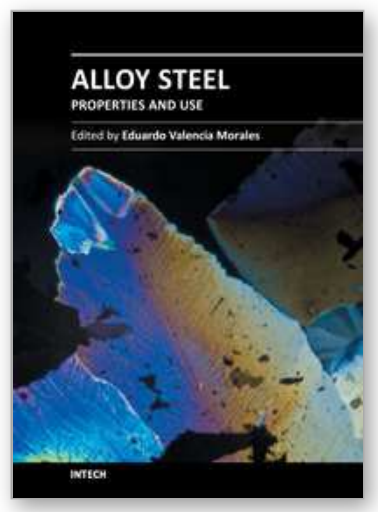

\author{
Alloy Steel - Properties and Use \\ Edited by Dr. Eduardo Valencia Morales
}

ISBN 978-953-307-484-9

Hard cover, 270 pages

Publisher InTech

Published online 22, December, 2011

Published in print edition December, 2011

The sections in this book are devoted to new approaches and usages of stainless steels, the influence of the environments on the behavior of certain classes of steels, new structural concepts to understand some fatigue processes, new insight on strengthening mechanisms, and toughness in microalloyed steels. The kinetics during tempering in low-alloy steels is also discussed through a new set-up that uses a modified Avrami formalism.

\title{
How to reference
}

In order to correctly reference this scholarly work, feel free to copy and paste the following:

E. El-Kashif and T. Koseki (2011). Effect of Niobium on HAZ Toughness of HSLA Steels, Alloy Steel Properties and Use, Dr. Eduardo Valencia Morales (Ed.), ISBN: 978-953-307-484-9, InTech, Available from: http://www.intechopen.com/books/alloy-steel-properties-and-use/effect-of-niobium-on-haz-toughness-of-hslasteels

\section{INTECH}

open science | open minds

\author{
InTech Europe \\ University Campus STeP Ri \\ Slavka Krautzeka 83/A \\ 51000 Rijeka, Croatia \\ Phone: +385 (51) 770447 \\ Fax: +385 (51) 686166 \\ www.intechopen.com
}

\author{
InTech China \\ Unit 405, Office Block, Hotel Equatorial Shanghai \\ No.65, Yan An Road (West), Shanghai, 200040, China \\ 中国上海市延安西路65号上海国际贵都大饭店办公楼 405 单元 \\ Phone: +86-21-62489820 \\ Fax: $+86-21-62489821$
}


(C) 2011 The Author(s). Licensee IntechOpen. This is an open access article distributed under the terms of the Creative Commons Attribution 3.0 License, which permits unrestricted use, distribution, and reproduction in any medium, provided the original work is properly cited. 